\title{
COMPLEMENTAÇÃO DA IRRIGAÇÃO E ÉPOCAS DE COLHEITA DE MANDIOCA CV. COQUEIRO NO PLANALTO DE CONQUISTA, BA
}

\author{
Water management and harvest time on cassava cv coqueiro in \\ Planalto de Conquista, BA
}

\author{
André Cândido Lopes ${ }^{1}$, Anselmo Eloy Silveira Viana², Sylvana Naomi Matsomoto², \\ Nelson dos Santos Cardoso Júnior³, Alcebíades Rebolças São José ${ }^{3}$
}

\begin{abstract}
RESUMO
Com o objetivo de avaliar o efeito da irrigação e épocas de colheita, sobre a produtividade e características agronômicas da mandioca (Manihot esculenta Crantz), conhecida como Coqueiro, foi desenvolvido um ensaio em condições de sequeiro e irrigado. $\mathrm{O}$ delineamento experimental foi em blocos casualisados, com quatro repetições, tendo como tratamentos as épocas de colheita $(8,10$, 12, 14, 16 e 18 meses após o plantio). Os resultados permitiram concluir que plantas irrigadas apresentaram valor de índice de área foliar 39\% maiores e valores de altura 14\% maior que plantas cultivadas em sequeiro. A produtividade de raízes não foi influenciada, significativamente, pela irrigação, mas aumentou linearmente com a idade e épocas de colheita. Aos 18 meses, plantas de mandioca produziram $40.590,60 \mathrm{~kg} \mathrm{ha}^{-1}$ de raízes, incremento de $100 \%$ em relação à colheita efetuada aos 8 meses. A percentagem de amido em raízes, em cultivo de sequeiro, decresceu com as épocas de colheita. Sob irrigação, a partir dos 14 meses, essa tendência se modificou com aumento dos valores.
\end{abstract}

Termos para indexação: Manihot esculenta, produtividade,raízes, amido, indice de area foliar, espaçamento.

\section{ABSTRACT}

In order to assess the effect of irrigation and harvest time on productivity and other agronomical characteristics of cassava (Manihot esculenta Crantz) known as Coqueiro, one experiment was developed under conditions of dry land and irrigation. A randomized block design was applied, with four replicates and treatments composed by different harvest seasons $(8,10,12,14,16$ and 18 months after planting). Plants submitted to irrigation had a $39 \%$ increase in leaf area and $14 \%$ in height, in comparison to those on dry land. Irrigation did not affect root productivity, but increase linearly according to harvest time. 18 months after being sowed, a root productivity of 40,590.60 $\mathrm{kg} \mathrm{ha}^{-1}$ was obtained, an increment of $100 \%$ in comparison to harvest realized in an 8-month period. The starch content of roots, cultivated without irrigation, had a tendency to decrease in relation to harvest time. With irrigation, this tendency was reverted, with an increase of values.

Index terms: Manihot esculenta, productivity of roots, starch, leaf area index.

(Recebido em 16 de fevereiro de 2007 e aprovado em 30 de julho de 2009)

\section{INTRODUÇÃO}

A mandioca (Manihot esculenta Crantz), euforbiácea com origem geográfica e agrícola na América Tropical (Allem, 2002), é um dos cultivos mais importantes para os trópicos em razão da grande amplitude de aplicação para a alimentação humana e animal (El-Sharkawi, 2006). A cultura apresenta produtividade média de raízes, de 10,70 $\mathrm{t} \mathrm{ha}^{-1}$ (Food and Agricultural Organization-FAO, 2005) valor inferior ao seu potencial produtivo de $90 \mathrm{t} \mathrm{ha}^{-1}$ deraízes frescas (Cock et al., 1979). Em 2005, o Brasil produziu 25,73 milhões de toneladas de raízes de mandioca com área cultivada de 1,89 milhões de hectares e rendimento médio de $13,63 \mathrm{t} \mathrm{ha}^{-1}$ (Instituto Brasileiro de Geografia e Estatística-IBGE, 2006). Dentre as causas que contribuem para a baixa produtividade da mandioca no Brasil, destaca-se a falta de variedades adaptadas às diferentes condições de cultivo, a realização inadequada ou ausência de práticas culturais, o uso de material de plantio de baixa qualidade, bem como o cultivo em regiões com precipitação anual menor que 1.000 a 1.500 $\mathrm{mm}$, índices considerados adequados para a cultura (Oliveira et al., 2006). O Estado da Bahia é um dos principais produtores de mandioca do Brasil, com produção de 4,56 milhões de toneladas e produtividade média de $12,80 \mathrm{t} \mathrm{ha}^{-1}$, no ano de 2005 (IBGE, 2006). Destaca-se, como uma das maiores zonas produtoras desta euforbiácea, o Planalto de Conquista, onde grande parte dos municípios tem na cultura uma das principais fontes de renda agrícola (IBGE, 2005). De acordo com estudos realizados por Silva et al. (2007), esta região apresenta temperaturas médias mínimas de $16,1^{\circ} \mathrm{C}$ e

${ }^{1}$ Praça JK - 60 - Alvorada - Salinas, MG - accandido@yahoo.com.br

2Universidade Estadual do Sudoeste da Bahia/UESB - Vitoria da Conquista, BA

3Universidade Estadual do Sudoeste da Bahia/UESB - Salinas, MG 
médias máximas de $26,4^{\circ} \mathrm{C}$, valores que caracterizam condição amena em comparação com as zonas tradicionais de cultivo de mandioca. As altitudes são elevadas, variando entre 900 a $1000 \mathrm{~m}$, com precipitação média anual de $700 \mathrm{~mm}$. No ano de 2005, a produção do município de Vitória da ConquistaBA foi de 23,40 mil toneladas de mandioca, em uma área de 1,80 mil hectares, com rendimento médio de $13 \mathrm{t} \mathrm{ha}^{-1}$ (IBGE, 2006). A irregularidade de ocorrência de chuvas, na região Sudoeste do Estado da Bahia, tem reduzido a produtividade de raízes e alongado o ciclo, dificultando a exploração dessa euforbiácea. Com o desenvolvimento da cultura na região e a crescente utilização da mandioca como componente de rações para alimentação animal, existe a busca por informações sobre a resposta desta cultura à irrigação. Embora exista uma base de conhecimento satisfatória sobre a implementação do suprimento hídrico por meio da irrigação para a cultura da mandioca, a interação com práticas de manejo regionais relacionados com a densidade e arranjo populacional e fatores climáticos locais necessita ser analisada. Tal interesse visa a aumentar a produtividade $\mathrm{e}$ reduzir o ciclo, possibilitando retorno de receita maior e mais rápido aos produtores que apresentam condições financeiras e/ou tecnológicas para adoção esta prática agrícola.

Conduziu-se este trabalho, com o objetivo de avaliar o efeito da irrigação e de épocas de colheita, sobre a produtividade e outras características agronômicas da cultivar Coqueiro de mandioca, no Planalto de Conquista, Ba.

\section{MATERIAL E MÉTODOS}

Um experimento foi conduzido em condições de sequeiro e irrigado, na Área Experimental do Campus da Universidade Estadual do Sudoeste da Bahia, em Vitória da Conquista - BA, município localizado no Sudoeste do Estado da Bahia, a 1451' de latitude Sul, 4050' de longitude Oeste, à altitude média de $928 \mathrm{~m}$. Durante o período do estudo, as médias das temperaturas máxima e mínima foram, respectivamente de 25,3 e $16,1^{\circ} \mathrm{C}$. A precipitação média anual foi de $733,9 \mathrm{~mm}$, sendo o maior nível encontrado de novembro a março. Nas Figuras 1 e 2, estão apresentados os dados climáticos durante o período de condução do experimento, referente à precipitação pluvial (mm), a umidade relativa do ar (\%), a temperatura média máxima $\left({ }^{\circ} \mathrm{C}\right)$ e a temperatura média mínima $\left({ }^{\circ} \mathrm{C}\right)$.

$\mathrm{O}$ solo da área experimental foi classificado como Latossolo Amarelo Álico A moderado, relevo plano, textura franco argilo arenosa, apresentando os seguintes resultados de acordo com a análise química da amostra se solo coletada na área experimental ${ }^{(4)}$ : $\mathrm{PH}$ em $\mathrm{H}_{2} \mathrm{O}(1: 2,5)$ $=5,5 ; \mathrm{P}\left(\mathrm{mg} / \mathrm{dm}^{3}\right)^{(5)}=3,5 ; \mathrm{K}^{+}\left(\mathrm{cmol} / \mathrm{dm}^{3}\right)^{(7)}=0,41 ; \mathrm{Al}^{3+}$ $\left(\mathrm{cmol} / \mathrm{dm}^{3}\right)^{(6)}=0,10 ; \mathrm{Ca}^{2+}\left(\mathrm{cmol} / \mathrm{dm}^{3}\right)^{(8)}=2,75 ; \mathrm{Mg}^{2+}(\mathrm{cmol}$ $\left./ \mathrm{dm}^{3}\right)^{(8)}=1,60 ; \mathrm{H}++\mathrm{Al}^{3+}\left(\mathrm{cmol} / \mathrm{dm}^{3}\right)^{(7)}=2,70 ;$ S.B. $(\mathrm{cmol} /$ $\left.\mathrm{dm}^{3}\right)=4,75 ; \mathrm{m}(\%)=3,0 ; \mathrm{V}(\%)=62,0 ;$ CTC efetiva $(\mathrm{cmolc}$ $\left./ \mathrm{dm}^{3}\right)=4,85 ;$ CTC a pH $=7,0\left(\mathrm{cmolc} / \mathrm{dm}^{3}\right)=7,45$. Em função da análise química de solo, determinou-se a necessidade de adubação, não sendo realizada calagem. O preparo do solo constou de sulcos, espaçados de um metro, foram abertos com sulcador mecânico e as manivas, distribuídas a cada $0,60 \mathrm{~m}$ dentro de cada sulco, definindo espaçamento de 1,0 x 0,60 m, sendo cobertas com uma camada de terra de $5 \mathrm{~cm}$. As manivas foram obtidas de frações do terço médio da planta, com $20 \mathrm{~cm}$ de comprimento e 2 a $3 \mathrm{~cm}$ de diâmetro, perfazendo uma média de oito gemas, sendo realizado corte reto nas duas extremidades, com facão. Efetuou-se o plantio em novembro de 2004, com a variedade conhecida localmente como Coqueiro, indicada para uso culinário, para produção de farinha e extração de amido.

Utilizou-se a irrigação por aspersão fixa, com bocal

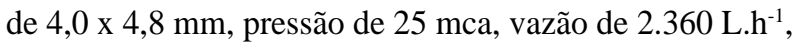
diâmetro irrigado de $29 \mathrm{~m}$, espaçamento 18 x $18 \mathrm{~m} \mathrm{e}$ precipitação de $7,3 \mathrm{~mm} \cdot \mathrm{h}^{-1}$. Para a avaliação da uniformidade de distribuição da irrigação, foi determinado um valor igual a $60 \%$, segundo metodologia do Coeficiente de Uniformidade de Christiansen (CUC) (Bernardo, 1982). O manejo da lâmina de água para irrigação foi determinado pelo método do tanque classe A. Semanalmente, foram coletadas amostras de solo para determinação da umidade, por meio do método gravimétrico (Topp \& Ferré, 2002) e comparada com a umidade referência da Capacidade de Campo, determinada por meio da saturação de $4 \mathrm{~m}^{2}$ de área, protegida contra a evaporação e, após 48 horas, foi determinada a umidade referência da capacidade de campo a profundidade efetiva escolhida para a cultura $(30 \mathrm{~cm})$, assumindo o valor de $15 \%$. Em função do período chuvoso foi suspensa a irrigação.

No quinto mês após o plantio (final de março/início de abril de 2005), época em que a planta entra em repouso vegetativo em razão de a temperatura atingir valores próximos à $15^{\circ} \mathrm{C}$, a irrigação foi suspensa. Nesse período ocorre na região maior acúmulo de massa seca nas raízes, caracterizando-se como época ideal de colheita. A irrigação foi retomada no reinício da fase de crescimento vegetativo (outubro de 2005). No final de março e início

\footnotetext{
${ }^{4}$ Análise realizada no Laboratório de Solos da UESB.

${ }^{5}$ Extrator Mehlich-1.

${ }^{6}$ Extrator $\mathrm{KCl} 1 \mathrm{~mol} . \mathrm{L}^{-1}$

${ }^{7}$ Extrator Solução SMP, pH 7,5 a 7,6.
} 
de abril de 2006, quando a cultura entrou no segundo período de repouso fisiológico, a irrigação foi novamente suspensa até a última colheita, realizada no mês de maio desse mesmo ano.

Cada parcela, com área total de $36 \mathrm{~m}^{2}$, foi composta por 26 plantas úteis. $\mathrm{O}$ experimento foi instalado em blocos casualisados, com quatro repetições e seis tratamentos, definidos por idade e épocas de colheita $(8,10,12,14,16$, 18 meses após o plantio). As plantas foram colhidas nos meses de julho, setembro, novembro de 2005 e janeiro, março e maio de 2006. A análise estatística foi realizada utilizando-se o programa Sistema para Análises Estatísticas e Genéticas (SAEG) versão 8.0 (Ribeiro Júnior, 2001). Para estudo da idade e épocas (meses) de colheita, utilizou-se a análise de regressão, enquanto os sistemas de cultivo foram comparados pelo teste F. Avaliaram-se as seguintes características: altura das plantas no momento da colheita; índice de área foliar - determinada a partir da relação entre área foliar total e a área do solo disponível para a planta, obtida pelo espaçamento utilizado; produtividade de raízes; percentagem de amido, estimada pelo método da balança hidrostática (Grossmann \& Freitas, 1950).

\section{RESULTADOS E DISCUSSÃO}

Foi verificada maior altura de plantas submetidas à irrigação $(2,87 \mathrm{~m})$, em relação às cultivadas em condição de sequeiro $(2,50 \mathrm{~m})$. Quando a disponibilidade de água foi mantida pela suplementação da irrigação, a arquitetura da copa das plantas foi alterada em razão do autosombreamento mais intenso verificado nas poções apicais do caule. Provavelmente, a elevação da densidade de plantas resultante do espaçamento definido pelos índices inferiores das recomendações de plantio (Mattos, 2006) acentuou a restrição da incidência luminosa pela interação entre as copas das plantas. De acordo com Aguiar (2003), os espaçamentos utilizados nos cultivos comerciais de mandioca de mesa são extremamente diversos, variando de 1,00 a 1,30 m entre linhas de plantio, com ajustes entre as plantas dentro da linha, que originam populações de 10.000 a 20.000 plantas.ha-1 aproximadamente. O hábito de crescimento, o porte das plantas cultivadas, juntamente com fatores edáficos e climáticos determinam a intensidade da competição por água, nutrientes e, principalmente, luz, devendo esses fatores serem levados em consideração à escolha do número de plantas mais adequado às condições locais. No presente estudo, o crescimento e manutenção de folhas nas regiões de alongamento do caule resultaram em restrição de incidência de luz, condicionando o estiolamento da planta. A tendência da planta de mandioca apresentar crescimento vegetativo exuberante, em condições favoráveis de clima e solo foi descrita por Fukuda \& Otsubo (2005), em plantios com espaçamentos 1,0 x $0,6 \mathrm{~m}$ e Amanullah et al. (2006), utilizando espaçamento de $0,90 \times 0,90 \mathrm{~m}$. Entretanto, tal estímulo ao crescimento vegetativo das plantas deve ser cuidadosamente avaliado no manejo da irrigação, quando a finalidade de produção é a raiz. Okogbenin et al. (2003) verificaram uma ampla variabilidade de comportamento na produção de massa fresca da parte aérea entre nove clones de mandioca submetidos a diferentes níveis de disponibilidade hídrica, cultivados em espaçamento $1,0 \times 1,0 \mathrm{~m}$. No referido estudo, para os genótipos cujo crescimento vegetativo foi mais vigoroso, a redução no crescimento, ocasionada por baixa disponibilidade hídrica, foi mais pronunciada na parte aérea que nas raízes.

Foi definido o modelo quadrático para a relação entre épocas de colheita e altura de plantas, indicando que esta característica aumentou lentamente, no período de 8 a 12 meses após plantio, em razão da condição temperatura e pluviosidade restritivas ao crescimento vegetativo (Figura 3).

Um incremento mensal médio de $3,91 \mathrm{~cm}$ foi observado no período de 8 a 12 meses após plantio e, posteriormente, entre 12 a 18 meses, tal índice atingiu $12,38 \mathrm{~cm}$. O incremento em altura foi mais intenso nesse período, em razão da elevação da temperatura e ocorrência de maiores índices pluviométricos. Como já comentado anteriormente, tais fatores favoreceram a expansão e manutenção das folhas nas porções apicais do caule, induzindo ao estiolamento. A menor flutuação da altura, durante o período de estudo foi decorrente de seu principal componente, o comprimento da haste principal ter como variante, apenas a porção apical (Figura 3). A vulnerabilidade da área foliar, principalmente em razão da abscisão induzida por fatores ambientais e fisiológicos, é mais elevada, pois, todas as folhas senescentes ou novas podem ser sensibilizadas, resultando em maior variação do índice de área foliar (determinado pela razão entre área foliar total da planta e espaçamento da cultura), como observado na Figura 4.

De maneira geral, a cultura apresentou índice de área foliar médio maior que 3,0, descrito por Cock (1982) como ideal para a mandioca, aos 12, 14 e 16 meses após plantio. Nos demais meses, o valor do índice de área foliar foi inferior ao considerado ideal (Tabela 1).

Plantas de mandioca submetidas à restrição hídrica reduzem expressivamente a transpiração por meio do rápido controle do fechamento estomático (El-Sharkawy, 2003), enrolamento (El-Sharkawy, 2007) e abscisão foliar das folhas mais velhas (Wright et al., 1983) e redução do crescimento 
de folhas novas (por restrição do alongamento e número de células) (Alves \& Setter, 2004a), em estudos realizados com plantas conduzidas em vasos de 3 litros). Conforme verificado por Alves \& Setter (2004b), em plantas conduzidas em vasos de 3 litros, a contribuição de mecanismos relativos ao ajustamento osmótico e acúmulo de proteínas do tipo dehidrinas é pouco expressivo para tal espécie. Tal fato foi considerado como uma característica favorável à adaptação da espécie sob condição de re-hidratação, pois a maior disponibilidade de reservas resultaria em fator positivo para a retomada de crescimento após a época de restrição hídrica e elevação da temperatura. No presente estudo, esse comportamento foi verificado, sendo refletido na variação do índice de área foliar, provavelmente, em função da umidade (que aumentou a partir de outubro, com a retomada da irrigação) e da temperatura (menor no mês de maio e julho) (Tabela 2).

Desse modo, embora a diferença tenha sido verificada apenas no mês de janeiro, tendência geral de maior índice de área foliar para o cultivo irrigado foi observada nos meses de novembro, janeiro, e março, quando a irrigação foi usada e quando as temperaturas foram mais elevadas. Para os meses com temperaturas mais reduzidas e/ou quando a irrigação foi suspensa (maio, julho e setembro), as plantas cultivadas em sequeiro, mais adaptadas ao estresse, apresentaram tendência de maior índice de área foliar. De acordo com Santos \& Carlesso (1998), plantas submetidas à irrigação, apresentam menor resistência às situações de déficit hídrico no solo, enquanto plantas submetidas ao estresse hídrico gradual, ou quando a incidência da restrição hídrica ocorre no início do ciclo, a adaptação das plantas tem efeito mais brando. Corroborando com tal asserção, no presente estudo, foi observada amplitude maior de variação do índice de área foliar para as plantas irrigadas $(3,804)$ em relação às plantas mantidas em condição de sequeiro $(2,3424)$ (Figura 4).

Para o efeito de épocas de colheita dentro de cada sistema de cultivo, sobre a característica índice de área foliar, foi delineado o modelo cúbico, tanto no cultivo em sequeiro como no irrigado. Apesar da similaridade de modelos, foi verificada ocorrência mais tardia dos limites de variação máxima e mínima do índice de área foliar para as plantas mantidas sob cultivo em sequeiro, quando comparadas ao cultivo irrigado (Figura 4). Foi observado também que o índice de área foliar das plantas de mandioca cultivadas sob irrigação apresentou, de modo geral, valores mais elevados que os obtidos em plantas mantidas em condição de sequeiro. O novo declínio, que se seguiu a partir dos 14 meses (janeiro), ocorreu próximo do inicio do segundo período de repouso fisiológico das plantas, o qual foi condicionado mais uma vez pela redução da taxa de precipitação pluviométrica (para plantas em condição de sequeiro) e pela queda de temperatura (para plantas em condição de sequeiro e irrigado) (Figuras 1 e 2). A variação dessa característica apresentou padrão consistente com as condições ambientais da região, conforme descrito anteriormente. Para o estado do Mato Grosso do Sul, de acordo com Lorenzi et al. (2002) meses quentes e úmidos, são fatores que condicionam o vigor vegetativo das plantas e, contrariamente, condição de restrição hídrica e temperaturas baixas induzem a abscisão foliar, caracterizando o período de repouso fisiológico. Sagrilo et al. (2002), estudando três cultivares de mandioca no Estado do Paraná, conduzidas em espaçamento de 1,0 x 0,8m, constataram que o índice de área foliar total aumentou dos 14 aos 17 meses de idade (outubro a janeiro), favorecido pela elevada temperatura e pelo aumento da precipitação. Para o presente estudo, com o início do período chuvoso e o aumento das temperaturas máximas e mínimas, (Figuras 1 e 2), observado após os 10 meses, as plantas, já, no segundo ciclo vegetativo, retomaram o crescimento, o que resultou na elevação da atividade fotossintética e de seu índice de área foliar. Além desses fatores, a condição de dias longos, também verificada por Keating et al. (1985) também foi um fator que condicionou o crescimento da parte aérea, resultando em maior área foliar das plantas de mandioca das cultivares M Aus 7 e M Aus 10.

Houve efeito linear de épocas de colheita para produtividade de raízes de mandioca (Figura 5). O volume de produção da colheita aos 18 meses após o plantio foi de 40.590,60 $\mathrm{kg} \mathrm{ha}^{-1}$ de raízes, aumentando 100,94\% em relação à colheita efetuada aos oito meses (com 20.200,60 $\mathrm{kg} \mathrm{ha}^{-1}$ ). Foram constatados acréscimos mensais, no intervalo de colheita de 8 a 18 meses, de $2.039 \mathrm{~kg}$ de raízes por hectare.

Esses resultados foram semelhantes aos obtidos por Souza \& Fukuda (1989) que, ao avaliar 12 variedades de mandioca em Mato Grosso, cultivadas em espaçamento 1,0 x 0,60m, observaram elevação de $100 \%$ do volume de produção das colheitas realizadas aos 18 meses em comparação à quantidade de raízes colhidas aos 12 meses de idade. Esse fato foi atribuído à idade das plantas, e decorrente da ocorrência do período chuvosos nos últimos 6 meses de ciclo da cultura. Para Takahashi \& Gonçalo (2005), a colheita de mandioca pode ser efetuada a partir do oitavo até o vigésimo quarto mês após o plantio, com variações na produtividade de raízes e do percentual de amido. Segundo os mesmos autores, a época de colheita é o fator que mais influencia no rendimento industrial. 


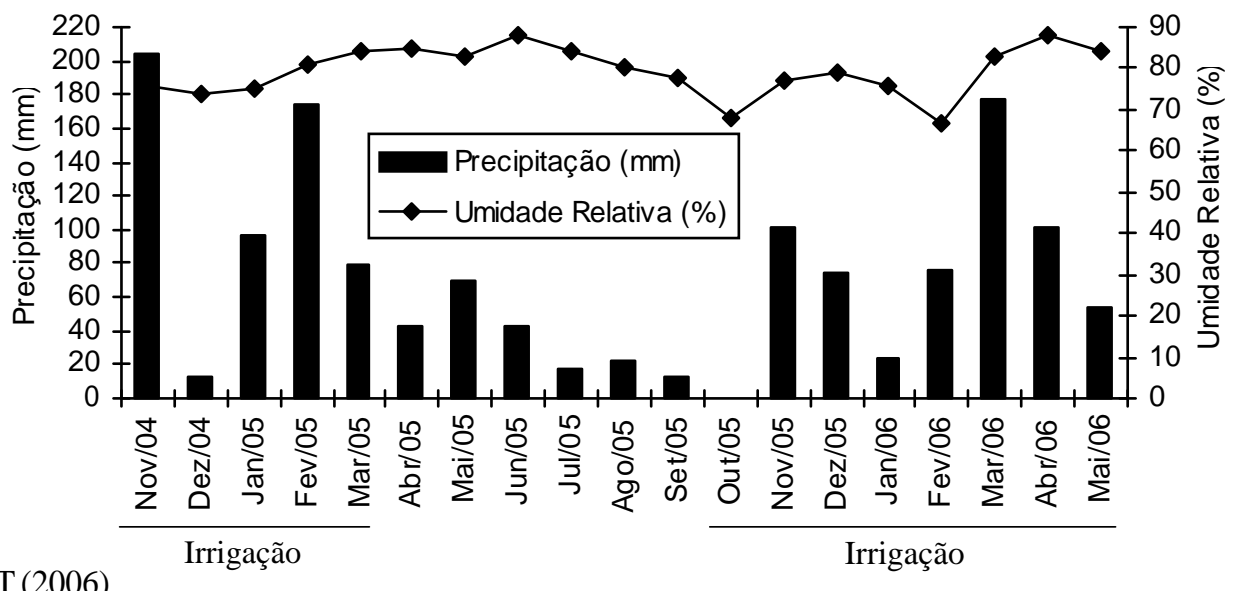

Fonte: INMET (2006)

Figura 1 - Médias mensais de precipitação pluviométrica e umidade relativa do ar, no período de novembro de 2004 a maio de 2006. Vitória da Conquista-BA, 2006.

Fonte: INMET (2006)

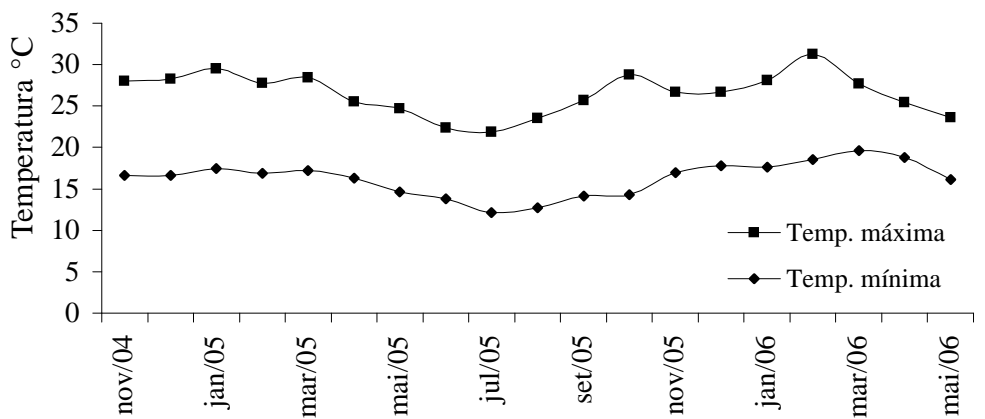

Figura 2 - Médias mensais de temperaturas máxima e mínima no período de novembro de 2004 a maio de 2006. Vitória da Conquista-BA, 2006.

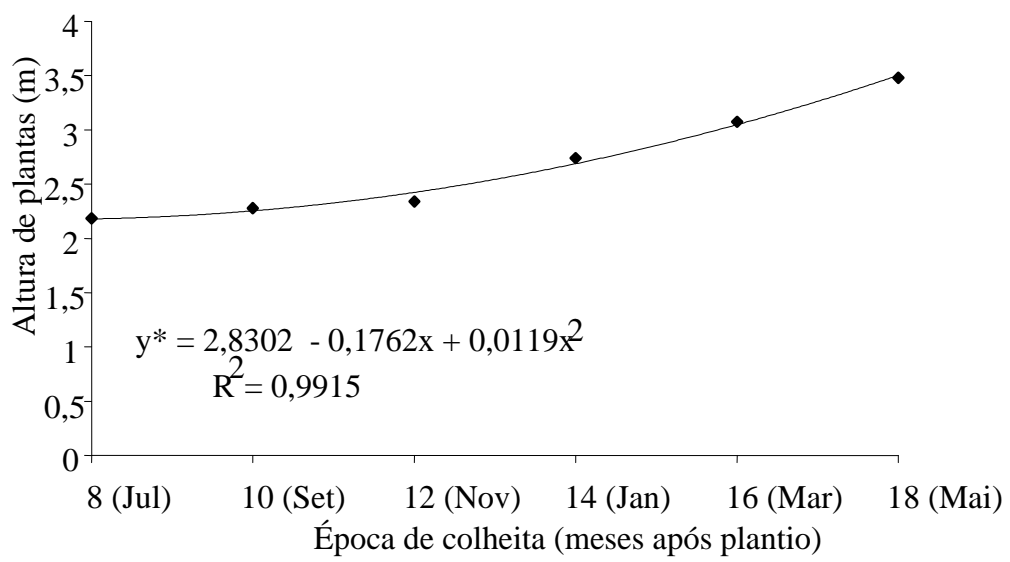

Figura 3 - Estimativa da altura de plantas de mandioca em função das épocas de colheita. Vitória da Conquista-BA. 2006.

* Significativo a 5\% de probabilidade, pela análise da regressão. 


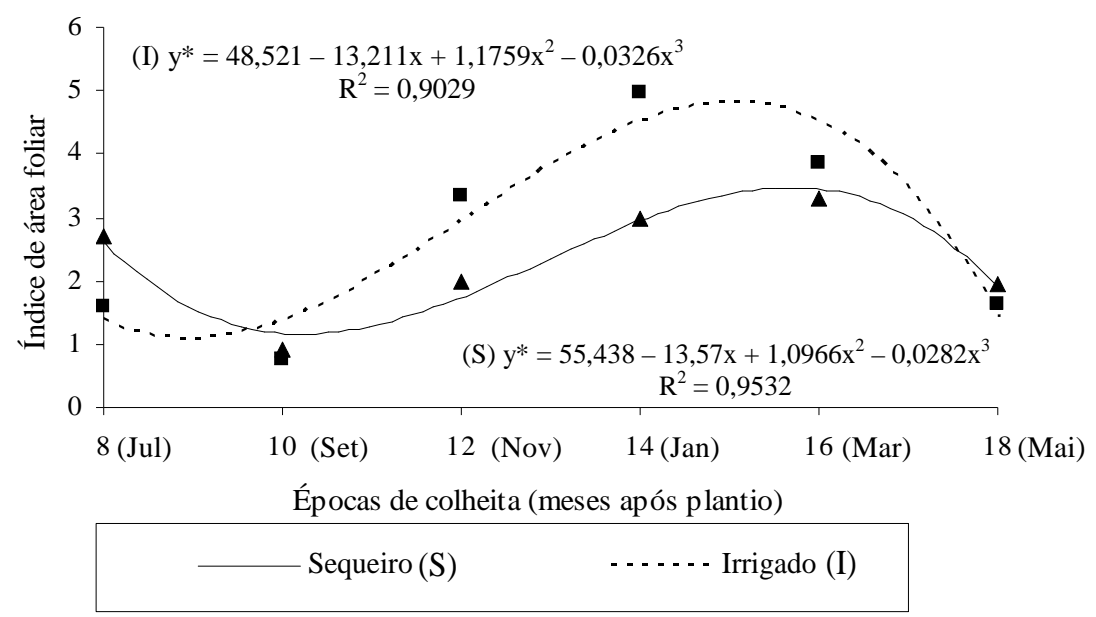

Figura 4 - Estimativa do índice de área foliar de mandioca em função das épocas de colheita em cultivo de sequeiro (S) e irrigado (I). Vitória da Conquista-BA. 2006.

* Significativo a 5\% de probabilidade, pela análise da regressão.

Tabela 1 - Médias de índice de área foliar em seis épocas de colheita da cultura da mandioca em cultivo de sequeiro e irrigado, avaliados no momento da colheita. Vitória da Conquista-BA, 2006.

\begin{tabular}{|c|c|c|c|c|c|c|c|}
\hline \multirow[b]{2}{*}{ Cultivo } & \multicolumn{6}{|c|}{ Épocas de colheita (meses) } & \multirow{2}{*}{ Médias } \\
\hline & $8(\mathrm{Jul})$ & 10 (Set) & 12 (Nov) & 14 (Jan) & 16 (Mar) & 18 (Mai) & \\
\hline Sequeiro & $2,68 \mathrm{a}$ & $0,88 \mathrm{a}$ & $2,01 \mathrm{a}$ & $2,98 \mathrm{~b}$ & $3,30 \mathrm{a}$ & $1,95 \mathrm{a}$ & $2,30 \mathrm{a}$ \\
\hline Irrigado & $1,58 \mathrm{a}$ & $0,75 \mathrm{a}$ & $3,32 \mathrm{a}$ & $4,98 \mathrm{a}$ & $3,87 \mathrm{a}$ & $1,64 \mathrm{a}$ & $2,69 \mathrm{a}$ \\
\hline Médias & 2,14 & 0,82 & 2,66 & 3,98 & 3,59 & 1,79 & \\
\hline
\end{tabular}

Médias seguidas de mesma letra na coluna não diferem entre si pelo teste $\mathrm{F}$ a $5 \%$ de probabilidade.

Tabela 2 - Médias da percentagem de amido avaliado em raízes, em seis épocas de colheita da cultura da mandioca em cultivo de sequeiro e irrigado, avaliados no momento da colheita. Vitória da Conquista-BA, 2006.

\begin{tabular}{|c|c|c|c|c|c|c|c|}
\hline \multirow[b]{2}{*}{ Cultivo } & \multicolumn{6}{|c|}{ Épocas de colheita (meses) } & \multirow{2}{*}{ Médias } \\
\hline & $8(\mathrm{Jul})$ & 10 (Set) & 12 (Nov) & 14 (Jan) & 16 (Mar) & 18 (Mai) & \\
\hline Sequeiro & $28,28 \mathrm{a}$ & $28,13 \mathrm{a}$ & $25,13 \mathrm{a}$ & $25,07 \mathrm{a}$ & $22,48 \mathrm{~b}$ & $23,76 \mathrm{~b}$ & 25,47 \\
\hline Irrigado & 28,36 a & $27,27 \mathrm{a}$ & $24,03 \mathrm{a}$ & $25,67 \mathrm{a}$ & $25,08 \mathrm{a}$ & $26,08 \mathrm{a}$ & 26,08 \\
\hline Médias & 28,32 & 27,70 & 24,58 & 25,37 & 23,78 & 24,92 & \\
\hline
\end{tabular}

Médias seguidas de mesma letra na coluna não diferem entre si pelo teste $\mathrm{F}$ a $5 \%$ de probabilidade.

Em razão do manejo temporal da irrigação, desde o plantio (novembro 2004) até o início do período de repouso vegetativo da cultura (abril 2005) e reaplicada na fase de crescimento vegetativo (outubro de 2005 a março de 2006), tal suplementação hídrica não promoveu elevações para a produção de raízes, considerada como principal fonte de renda da cultura. Em média, a produtividade de raízes de plantas de mandioca irrigadas foi de $29.526,80 \mathrm{~kg} \mathrm{ha}^{-1} \mathrm{e}$ de plantas cultivadas em regime de sequeiro, $31.263,77 \mathrm{~kg} \mathrm{ha}^{-1}$.
Condições de precipitação bem distribuída resultam em vigor do crescimento da cultura da mandioca sem necessidade de irrigação, entretanto, em condições que apresentam restrição hídrica, culturas irrigadas podem apresentar rendimentos de 150 a $200 \%$ maior (Kerala Agricultural University, 2002).

Maior percentagem de amido em raízes de plantas irrigadas foi verificada em relação às cultivadas em sequeiro, somente quando a colheita foi realizada aos 16 e 18 meses 
após o plantio (Tabela 2). Entretanto, em estudo realizado por Santipastori et al. (2001), os teores de amido foram sensivelmente reduzidos em todas as avaliações realizadas para períodos de colheita entre 6 a 12 meses de ciclo da cultura. No presente estudo, para as plantas irrigadas, no final de julho a início de agosto, até o mês de janeiro, o efeito da maior disponibilidade hídrica em relação ao cultivo em sequeiro não foi evidenciado, em razão do direcionamento de carboidratos da raiz para a parte aérea da plantas, que favoreceram maior vigor vegetativo. Evidências sobre tal comportamento foram descritos anteriormente a partir dos modelos delineados para índice de área foliar (Figura 4). De acordo com Sriroth (2001), para plantas com boa suplementação hídrica no início do desenvolvimento a capacidade de regeneração do crescimento vegetativo ocorre em detrimento do consumo do material de reserva das raízes, resultando na queda dos teores e da qualidade do amido.
No presente estudo, apesar do decréscimo dos teores de amido observado para o sistema de manejo irrigado e sequeiro durante o período do estudo, comportamento diferenciado foi definido pela tendência de elevação em relação ao tempo de colheita a partir dos 14,24 meses, em plantas irrigadas. Para as plantas cultivadas sob condição de sequeiro, o decréscimo dos teores foi evidente, durante todo o período de colheita em estudo. Sriroth (2001) verificou que, para plantas submetidas às condições de restrição hídrica, sem especificação de espaçamento de plantio, no início do ciclo da cultura, o crescimento e a síntese de amido só ocorrem após o re-estabelecimento de condições hídricas favoráveis. Para o presente estudo, apesar da recuperação do crescimento da cultura, os efeitos quantitativos promovidos pela restrição hídrica incidentes no início do ciclo da cultura resultaram em queda irreversível para a capacidade de acúmulo de amido da raiz.

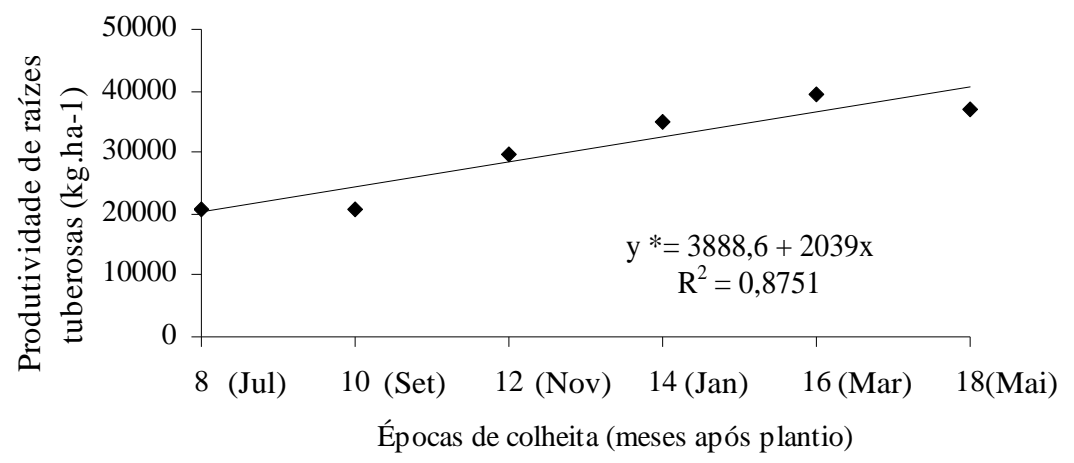

Figura 5 - Estimativa da produtividade de raízes da cultura da mandioca em função das épocas de colheita. Vitória da Conquista-BA. 2006.

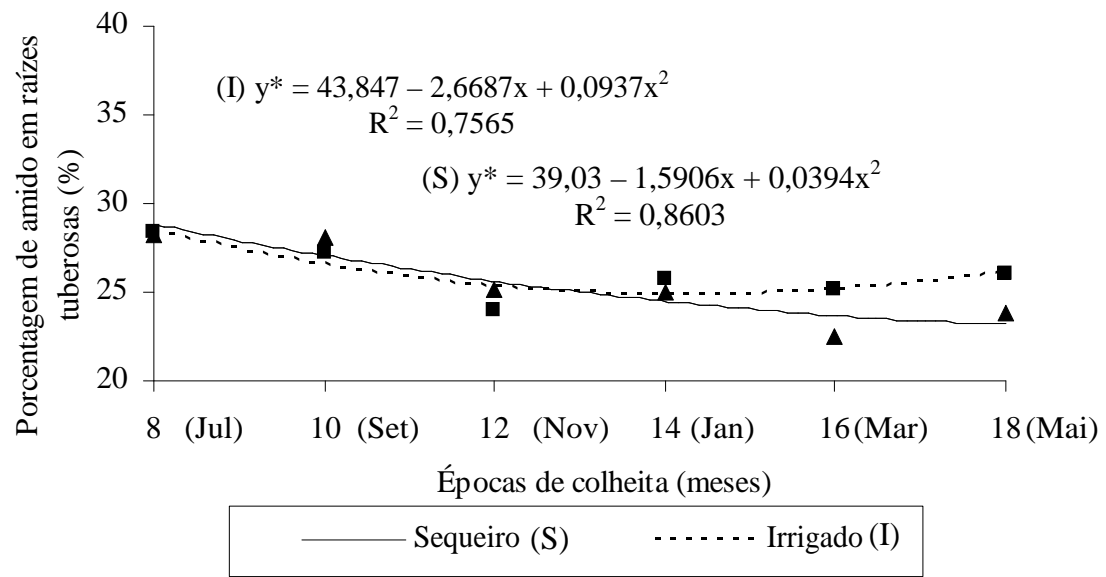

Figura 6 - Estimativa da percentagem de amido em raízes de mandioca em função das épocas de colheita em cultivo de sequeiro (S) e irrigado (I). Vitória da Conquista-BA. 2006.

* Significativo a 5\% de probabilidade, pela análise da regressão. 
Cavalcanti (1994) verificou que a maior disponibilidade de água nos experimentos irrigados favoreceu o acúmulo de amido em raízes, em estudos realizados sobre a avaliação do comportamento de algumas cultivares de mandioca, em espaçamento $1,0 \times 1,0 \mathrm{~m}$, na região Semiárida do Nordeste Brasileiro. Borges et al. (2002), avaliando variedades de mandioca em Cruz das Almas, Bahia, conduzidas em espaçamento 1,00 x 0,60 m, verificaram que o teor de amido variou de acordo com as variedades, épocas de colheita e anos agrícolas. Em vinte e seis variedades estudadas por esses autores, os teores de amido oscilaram entre 24,89 e $33,55 \%$.

\section{CONCLUSÕES}

Os resultados apresentados neste trabalho permitem concluir que, nas condições em que o experimento foi conduzido para a cultivar Coqueiro:

- Plantas irrigadas apresentaram valores 39\% e 14\% maiores que plantas cultivadas em sequeiro, respectivamente, para índice de área foliar e altura.

- A produtividade de raízes aumentou linearmente com as épocas de colheita. A colheita, aos 18 meses após o plantio, produziu $40.590,60 \mathrm{~kg} \mathrm{ha}^{-1}$ de raízes, aumento de $100,94 \%$ em relação à colheita efetuada aos 8 meses. Essa característica não foi influenciada, pela irrigação.

- A produtividade de plantas irrigadas foi de $29.526,80 \mathrm{~kg} \mathrm{ha}^{-1} \mathrm{e}$, em cultivo de sequeiro, $31.263,77 \mathrm{~kg}$ ha${ }^{1} \mathrm{O}$ estímulo ao maior vigor vegetativo, determinado pela densidade de plantas elevada e pela irrigação foram fatores determinantes para tal comportamento.

- A percentagem de amido em raízes apresentou comportamento quadrático em função das épocas de colheita. Em cultivo de sequeiro, houve tendência de decréscimo dessas características com as épocas de colheita. Nas condições de irrigação, a partir dos 14 meses, essa tendência se modificou com aumento dos valores.

\section{REFERÊNCIAS BIBLIOGRÁFICAS}

AGUIAR, E.B. Produção e qualidade de raízes de mandioca de mesa (Manihot esculenta Crantz) em diferentes densidades populacionais e épocas de colheita. 2003. 90p. Dissertação (mestrado agricultura tropical e subtropical)-Instituto Agronômico de Campinas, Campinas, 2003.

ALLEM, A.C. The origins and taxonomy of cassava. In: HILLOCKS, R.J.; THRESH, J.M.; BELLOTI, A.C.

Cassava: biology, production and utilization. New York: CAB International, 2002. p.1-16.
ALVES, A.A.C.; SETTER, T.L. Response of cassava leaf area expansion to water deficit: cell proliferation, cell expansion and delayed development. Annals of Botany, London, v.94, p.605-613, 2004a.

ALVES, A.A.C.; SETTER, T.L. Abscisic acid accumulation and osmotic adjustment in cassava under water deficit. Environmental and Experimental Botany, v.51, p.259-271, 2004b.

AMANULLAH, M.M.; ALAGESAN, K.; VAIYAOURI, A.K.; PAZHANIVELAN, S.; SAHYAMOORTHI, K. Intercropping and organic manures on the growth and yield of cassava (Manihot esculenta Crantz.). Research Journal of Agriculture and Biological Sciences, v.2, n.5, p.183-189, 2006.

BERNARDO, S. Manual de irrigação. 2.ed. Viçosa, MG: UFV, 1982.

BORGES, M. de F. et al. Avaliação de variedades de mandioca para consumo humano. Pesquisa

Agropecuária Brasileira, Brasília, v.37, n.11, p.1559$1565,2002$.

CAVALCANTI, J. Comportamento produtivo de cultivares de mandioca em condições irrigadas e de sequeiro na região Semi-Árida. Revista Brasileira de Mandioca, Cruz das Almas, v.13, n.1, p.17-27, 1994.

COCK, J.H. Cassava: a basic energy source in the tropics. Science, New York, v.218, n.457, p.755-762, 1982.

COCK, J.H. et al. The ideal cassava plant for maximum yield. Crop Science, Madison, v.19, p.271-279, 1979.

El-SHARKAWY, M.A. Cassava biology and physiology. Plant Molecular Biology, Dordrecht, v.53, p.621-641, 2003.

El-SHARKAWY, M.A. International research on cassava photosynthesis, productivity, eco-physiology, and responses to environmental stresses in the tropics. Photosynthetica, v.44, n.4, p.481-512, 2006.

El-SHARKAWY, M.A. Physiological characteristics of cassava tolerance to prolonged drought in the tropics: implications for breeding cultivars adapted to seasonally dry and semiarid environments. Brazilian Journal of Plant Physiology, Piracicaba, v.19, n.4, p.257-286, 2007 
FOOD AND AGRICULTURAL ORGANIZATION.Faostat database gateway. Disponível em: <http: ://apps. fao org/ lim500/nph-wra. pl.Production.Crops.Primary\&Domain=SU>. Acesso em: 2 fev. 2005.

FUKUDA, C.; OTSUBO, A.A. Cultivo da mandioca na região Centro Sul do Brasil. Brasília: Embrapa Mandioca e Fruticultura, 2005. Disponível em: <http:// isistemasdeproducao.cnptia.embrapa.br/Fontes HTML Mandioca/mandioca_centrosul/irrigacão.html . Acesso em: 11 fev. 2005 .

GROSSMANN, J.; FREITAS, A.C. Determinação do teor de matéria seca pelo peso específico em raízes de mandioca. Revista Agronômica, v.14 n.160/162, n.4, p.7580, 1950 .

\section{INSTITUTO BRASILEIRO DE GEOGRAFIA E} ESTATÍSTICA. Levantamento sistemático da produção agrícola - LSPA. Rio de Janeiro, 2006. 76p.

INSTITUTO BRASILEIRO DE GEOGRAFIA E ESTATÍSTICA. Sistema IBGE de recuperação automática - SIDRA. Disponível em: <http: ////Www.sidra.ibge.gov.bri bda/agric/>. Acesso em: 18 fev. 2005.

KEATING, B.A.; WISON, G.L.; EVENSON, J.P. Effect of photoperiod on growth and development of cassava (Manihot esculenta Crantz). Australian Journal of Plant Physiology, Melbourne, v.12, p.621-630, 1985.

KERALA AGRICULTURAL UNIVERSITY. Package of practices recommendations: crops. 12.ed. Trichur: Kerala Agricultural University, 2002. 278p.

LORENZI, J.O. et al. Aspectos fitotécnicos da mandioca em Mato Grosso do Sul. In: OTSUBO, A.A.; MERCANTE, F.M.; MARTINS, C. de S. (Coord.). Aspectos do cultivo da mandioca em Mato Grosso do Sul. Dourados: Embrapa Agropecuária Oeste/UNIDERP, 2002. p.77-108.

OKOGBENIN, I.; EKANAYAKE, I.J.; PORTO, M.C.M. Genotypic variability in adaptation responses of selected clones of cassava to drought stress in the Sudan savanna zone of Nigeria. Journal of Agronomy and Crop Science, Madison, v.189, p.376-389, 2003.

OLIVEIRA, S.L. de; COELHO, E.F.; NOGUEIRA, C.C.P. Irrigação. In: SOUZA, L. da S.; FARIAS, A.R.N.; MATOS, P.L.P. de; FUKUDA, W.M.G. (Eds). Aspectos socioeconômicos e agronômicos da mandioca. Cruz das Almas: Embrapa mandioca e fruticultura tropical, 2006. p.292-300.

RIBEIRO JÚNIOR, J.I. Análises estatísticas no SAEG. Viçosa, MG: UFV, 2001. 301p.

SAGRILLO, E. et al. Efeito da época de colheita no crescimento vegetativo, na produtividade e na qualidade de raízes de três cultivares de mandioca. Bragantia, Campinas, v.61, n.2, p.115-125, 2002.

SANTIPASTORI, V.; KUROTJANAWONG, K.; CHOTINEERANAT, S.; PIYACHOMKWAN, K.; SRIROTH, K.; OATES, C.G. Impact of water stress on yield and quality of cassava starch. Industrial Corps and Products, v.13, n.1, p.115-129, 2001.

SANTOS, F.R.; CARLESSO, R. Déficit hídrico e os processos morfológicos e fisiológicos das plantas. Revista Brasileira de Engenharia Agrícola e Ambiental, Campina Grande, v.2, n.3, p.287-294, 1998.

SILVA, R.C.; LIMA, E.M.; MAIA, M.R. Temperaturas extremas da cidade de Vitória da Conquista no período de 1997 a 2006: algumas considerações. In: SEMANA DE PESQUISA E PÓS-GRADUAÇÃO DA UESC, 9., 2007, Ilhéus. Anais...Ilhéus: Uesc, 2007. Disponível em: <http:/ izwww.seminarioicuesc.com br/sistema/resumosi $2007265 . \mathrm{pd} \uparrow$. Acesso em: 17 jun. 2008.

SOUZA, L.D.; FUKUDA, W.M.G. Avaliação de variedades de mandioca no Município de SINOP-MT em diferentes épocas de plantio e idades de colheita.

Revista Brasileira de Mandioca, Cruz das Almas, v.8, n.2, p.61-70, dez. 1989.

SRIROTH, K.S.; PIYACHOMKWAN, K.; SANTIPASTORI, V.; OATES, C. Environmental conditions during root development: drought constraint on cassava starch quality. Euphytica, Wageningen, v.120, p.95-101, 2001.

TAKAHASHI, M.; GONÇALO, S. A cultura da mandioca. Paranavaí: Olímpica, 2005. 116p.

WRIGHT, G.C.; SMITH, R.G.; McWILLIAM, J.R. Differences between two grain sorghum genotypes in adaptation to drought stress: I., crop growth rate and yield response. Australian Journal of Agricultural Research, Melbourne, v.34, p.615-626, 1983. 